\title{
Exploring University Administrators' Perceptions of Organisational Climate and Job Satisfaction in Two Ghanaian Universities: A Qualitative Case Study
}

\author{
Georgina, Asi Owusu* \\ Office of the Vice Chancellor, University of Cape Coast, Ghana \\ Kholeka Constance Moloi \\ Madina Institute South Africa, Cape Town, South Africa
}

\begin{abstract}
The focus of this study is on university administrators' perceptions about organisational climate and job satisfaction in two Ghanaian universities through a qualitative case study design. The research question posed is: How do administrators in the two Ghanaian universities perceive organisational climate and job satisfaction? Through purposive sampling, 16 (eight from each university) administrators were selected to participate in this study. Semi-structured, in-depth, individual interviews were conducted and analysed qualitatively. The study found that most administrative staff have negative perceptions about the organisational climate in their institutions and they reported to be dissatisfied with the work they do. It was also found that there is a direct link between organisational climate and job satisfaction. The study concludes that employee dissatisfaction among administrators is inimical to work quality and output. The study recommends that the government could partner with management of public universities to put mechanisms in place to ensure that administrative staff are satisfied with their work conditions and derive job satisfaction.
\end{abstract}

Keywords: Organisational climate, Job satisfaction, Ghanaian public university, Administrators

DOI: $10.7176 / \mathrm{JEP} / 11-21-13$

Publication date:July $31^{\text {st }} 2020$

\section{Introduction}

In this paper, we explore the perceptions of administrators about organisational climate and their job satisfaction within the context of two Ghanaian universities. Job satisfaction, the world over and in Ghana, has attracted some level of attention by the public, policy makers, educators, administrators and other stakeholders in the educational sector (Owusu, 2018; Okoli, and Monanu, 2016). Job satisfaction is a two-dimensional measure of workers' contentedness with their job, whether they like the job or individual aspects or facets of jobs, such as nature of work or supervision and it has intrinsic and extrinsic dimensions (Aziri, 2011). Intrinsic sources of satisfaction hinge on individual innate features such as capacity to use creativity, relate with superiors or the work that the individual concerned performs (Owusu, 2018; Okoli and Monanu, 2016). Extrinsic dimensions include security, salary and working conditions (Goetz, Campbell, Broge, and Dörfer, 2012).

Research by Abdirahan, Najeemdeen, Abidemi, and Ahmad (2018) shows that there is a close relationship between organisational climate and how employees generally perceive their job satisfaction and perform their duties. Berberoglu (2018) suggests that the attitudes and perceptions of employees can influence how they deliver the service. For Bin Shmailan (2016:1), successful organisations know that employee satisfaction, performance and employee engagement are crucial. Abdirahan et al. (2018), however, argue that employee job performance continues to be a major challenge in organisational administration globally. In his study on how task-oriented and relations-oriented leadership behaviours are positively related to the employees' perceptions of organisational climate, Holloway (2012) found that certain leadership behaviours have an impact on a few dimensions of organisational climate. A study by Telman and Unsal (2004) counted personal factors such as demographic characteristics (gender, age, length of service, educational level etc.) as factors that influence employee job satisfaction in an organisation.

Ghanaian public universities have been going through a sequence of reforms aimed at ensuring expanded access, quality and encouraging a high demand for tertiary education. Within the Ghanaian higher education sector, the role of university administrators in the successful delivery of quality tertiary education cannot be understated. According to Owusu and Owusu (2014), the administrators' role complements that of the faculty within the university set up to bring about desired results in the educational enterprise. Administrators' work has been described as a prime pillar in the sector of education delivery at tertiary levels. We posit that nations cannot make much gains without effective work of administrators. While government carries out expansionary works in public universities to cater for the yet-to-be-admitted free senior high school students, there is even more need for the universities to retain the required numbers of qualified administrative staff to carry out all scheduled academic programmes. However, there has been a continuous high labour turnover of capable and endowed administrative 
staff in most of the public universities in Ghana (Owusu, 2018). The disturbing situation is that most of the administrative staff in public universities do not stay in their jobs for long. Some of them migrate to other professions whenever there is the opportunity, thus causing brain drain.

\section{Problem statement}

The constant mobility of competent administrative staff in an era of expansionary works in public universities in Ghana may affect the government's intention to improve access and ensure quality, negatively. Ostensibly, this category of administrators leaves their job because of the perceived dissatisfactory conditions in which they work (Owusu, 2018). If no measures are taken to stem this tide, the institutions would be deprived of the competent human resources required to achieve their institutional goals. In other words, the exodus of this staff to other professions could have dire consequences on the quality delivery of tertiary education, thus jeopardising the good intents of government. To curb the practice and guarantee staff retention, welfare of all personnel, especially administrators, must be critically considered to retain them. Despite the importance of this matter, there is a dearth of qualitative research concerning organisational climate and job satisfaction of administrative staff in Ghana, hence the need for this study. This study provides the opportunity to advance the frontiers of knowledge through its engagement with administrators to have in-depth understanding of the issue on organisational climate and job satisfaction. The research question posed is: How do administrators in the two Ghanaian universities perceive organisational climate and job satisfaction?

\section{Theoretical framework}

The social exchange theory (SET) by Kieserling (2018) undergirds this case study. According to Tiwari (2017:1), sociologist George Homans (1961) was one of the first to discover the theory of social exchange theory in the late 1950s and early 1960s. George Homans, in 1958, created the social exchange theory. Social exchange theory holds that there are basically two main fundamental properties - the one is self-interest and the other is interdependence. Whenever there is an exchange between two parties, one individual is looking out for their own economic and psychological needs or benefits. In the context of this study, the benefit is job satisfaction of the selected administrators in two Ghanaian universities. Tiwari (2018) suggests that people want to satisfy themselves that their job needs are being fulfilled. Thus, when there is any social exchange, there is some sort of interdependence on one another and in the context of this study, organisational climate and the job satisfaction of administrators. Two parties are mutually dependent on one another for any kind of social exchange and for this study; the university management and the administrative staff. Tiwari (2018) suggests that if this dependence provides a positive outcome then the relationship will be maintained on good terms and will be continued; if in case the outcome is negative, the two parties will not work together. Within the framework of this theory (SET), the public university management (employer), we believe, is dedicated to fostering a long-term employment relationship with all administrative staff (employees). However, to achieve this, the management must satisfy the administrators' needs through the provision of favourable workplace climate, good working conditions, growth opportunities and relevant support. We believe that in return, the administrative staff (employees) will be devoted to delivering the expectations of the of the institution and continually improve their work output performance. Such a readiness to foster a long-term bond between the university management and administrative staff is one of the important features of the social exchange theory (Kieserling, 2018).

\section{Literature review}

Several empirical studies have been conducted on organisational climate and job satisfaction of employees in many organisations (Gaviria-Rivera and Lopez-Zapata, 2019; Das, 2018; Jyoti, 2014; Castro and Martins, 2010). However, these studies were conducted outside Ghana and the authors used quantitative research approaches. For example, Pangil, Yahya, Johari, Md Isa, and Daud (2011) investigated the relationship between organisational climate and job satisfaction among government agency officers in Malaysia, using a cross-sectional descriptive survey design. Deriving four dimensions of organisational climate (reward orientation, responsibility, structure and participation) from a principal component factor analysis, the authors found that all the dimensions of organisational climate are significant predictors of job satisfaction.

Three years later, Ahmed, Molla, and Abed (2014) similarly examined the effect of organisational climate on job satisfaction among clinical instructors at the Faculty of Nursing, Cairo University, Egypt, using a descriptive exploratory design. Their study showed that 63 percent of the sample had moderate perceptions of organisational climate and 55 percent had moderate levels of job satisfaction. There was a statistically significant difference in the perception of male and female employees on organisational climate $(\mathrm{t}=2.856, \mathrm{p}=.005)$. However, the study did not find any statistically significant difference between gender and job satisfaction $(t=.293, p=.770)$, although there was a perfect positive correlation between overall job satisfaction and organisational climate $(r=.679, p=.000)$ (Ahmed et al., 2014). The study concluded that clinical instructors had moderate levels of job satisfaction and organisational climate and that there are positive correlations between organisational climate and job satisfaction 
dimensions. Furthermore, the study concluded that there was no statistically significant difference between sociodemographic data and organisational climate and job satisfaction except that females had a more positive perception of organisational climate than male participants did.

Gaunya (2016) conducted a similar study to that of Ahmed et al., (2014) by employing a quantitative research approach, investigating organisational climate and its influence on job satisfaction among public sector employees in Kisii County, Kenya. He found that the dimensions of organisational climate such as appropriate administrative style, support from superiors and feedback about performance, identity, reward and conflict management variously influenced employees' job satisfaction dimensions such as work flexibility and security, lifelong learning and career development, work organisation and work life balance. The study also revealed that identity, conflict management and rewards (dimensions of organisational climate) had a substantial direct association with job satisfaction. The implication of this outcome was that public sector employees in Kisii County, Kenya are more satisfied with their work where organisational mission and objectives are in harmony with employees' personal beliefs.

Gaunya's (2016) study recommended that managers should foster an all-encompassing serene work environment to create sound social relations and sustain cordial relationships among colleagues and supervisors at the workplace. Gaunya (2016) further, encouraged managers of organisations to concentrate on articulating the mission of their organisation, while at the same time, inspiring a dynamic and high sense of employee identification. He also advocated for impartiality in conflict resolution processes as well as fairness and transparency in reward systems as sure strategies to enhance employee job satisfaction.

Okoli (2019) investigated the relationship between organisational climate and job satisfaction among academic staff in selected private universities in southeast Nigeria, using a survey design. The results of the study revealed that a positive significant correlation existed between organisational climate and job satisfaction. The results further showed that there is a significant relationship between organisational climate dimensions (leadership style and academic freedom) and job satisfaction dimensions (satisfaction with administrative support and satisfaction with working conditions). This, according to the study, implied that dissatisfaction among academic staff will not only affect quality of work, but also the organisational climate. The study suggested that university management should ensure that all academics receive the needed orientation and administrative support once they join the university. In the spirit of impartiality and fairness, university management should improve the existing working conditions of academic staff to avoid the feelings of bias, withdrawal and low drive among academic staff (Okoli, 2019).

\section{Methods}

A qualitative, interpretive research approach and case study design were used to explore the perceptions of administrators from two Ghanaian universities about organisational climate and job satisfaction. We found the case study design suitable for this study because, according to Yin (2017), a case study involves an up-close, indepth and detailed examination of a case in a bounded context. Since our motive was to understand what organisational climate and job satisfaction meant to the selected participants, it was important that we choose a methodology and design that would enable us to understand their subjective meanings and interpret their accounts accurately (Jameel, Shaheen, and Majid, 2018).

\subsection{Study participants}

The study was set in two public universities (university A and university B) in the central region of Ghana. The population consisted of all university administrators (senior staff and senior members) in the two universities, totalling 1420. From this population, a sample of 16 administrators ( 8 from each university), comprising both senior and junior staff members, was selected for in-depth, individual interviews. The sample comprised 6 males and 10 females. To conceal the identities of the participants, the researchers assigned them pseudonyms, namely participant 1A, 2A, 3A, 4A 5A, 6A, 7A, 8A for university A and participant 1B, 2B, 3B, 4B 5B, 6B, 7B and 8B for university $B$. The criteria for selection of the 16 participants included sufficient service years for the purpose of our study, ranging from three and a half to 22 years at their specific universities. We believed that these participants had sufficient experience to provide rich insights regarding their experiences and feelings about organisational climate and job satisfaction within their universities.

\section{Data collection method}

A semi-structured interview guide, with open-ended questions was used to collect data through in-depth, individual interviews with the selected participants (Britten, 1995). After receiving ethical clearance from the University of South Africa, where the principal researcher was pursuing her $\mathrm{PhD}$ studies (in 2018), and after permission was sought from the two selected universities, the principal researcher sent out consent letters to individual participants who had been identified for the study. Before the interviews were conducted, the researchers sought permission from the selected participants to record their accounts, for purposes of validating their responses. In the consent 
letter the principal researcher explained that the participants were being invited to participate in a study entitled: Influence of organisational climate on job satisfaction among administrative staff of two public universities in the central region of Ghana. The aim of the study was clarified. The principal researcher also explained that the study would entail data collection through semi-structured, in-depth, individual interviews of 30 minutes in length to take place at a mutually agreed location upon, at a time convenient to the participants. It was explained that during the interview, the participants had the right to decline to answer any of the interview questions if they so wished.

Furthermore, they should feel free to withdraw from the study at any time without any negative consequences. The benefits of the study were explained as highlighting factors that university administrators see as critical in enhancing job satisfaction within their institutions. It was explained that the study would entail low risk to participants and what steps would be taken to mitigate the risks. It was further explained that there would be no reimbursement or any incentives for participation in the research. To ensure rigour the interview transcripts would be sent back to them to cross-check information. The selected participants were also informed that the outcome of the research would be published in an on-line access journal and that the report of the study would be disseminated through conference presentations for public consumption.

Three interview questions guided the interviews were: How would you describe the climate of your institution? In which way does your university encourage professional development opportunities? Tell me, what gives you satisfaction in the work you do? Each one of the 16 participants were asked the same questions with probes where necessary. Data was collected until saturation was reached.

\section{Data Analysis}

The interview data was transcribed and analysed using Braun and Clarke's (2006) thematic content analysis. Through an inductive process we wanted to identify underlying ideas, patterns and assumptions that were expressed by the selected participants in order to answer the research question we posed: How do administrators in the two Ghanaian universities perceive organisational climate and job satisfaction? In our choice for thematic content analysis we also aimed to meet trustworthiness criteria outlined by Lincoln and Guba (1985), namely: the criteria of credibility, transferability, dependability and confirmability. Thematic content analysis is a six-phase process that is both iterative and reflective. The process involves a constant moving back and forward between phases, as suggested by Nowell, Norris, White and Moules (2017:1) to organise and prepare the data for analysis; as well as to describe/interpret the themes aimed at ensuring that accurate information is validated (Newby, 2010:62). Data analysis process involved a rigorous process of data familiarisation, data coding, theme development and revision.

In phase one we read through the entire data set once before beginning coding (Nowell et al., 2017:3). We then familiarised ourselves with the data by reading and re-reading the data to become immersed and intimately familiar with its content. We then searched for patterns and meanings, which led to the process of manual coding using numbers which were collated to identify broader patterns of meaning together with all relevant data extracts, for later stages of analysis (Nowell et al., 2017:3). Phase two involved the production of codes from the data, and we kept revisiting the data, reflecting on it, interacting and thinking about it (Wong, 2008:14), focusing on specific aspects of the data. In phase three we sorted and collated relevant coded data extracts into ten themes (Braun and Clarke, 2006; Creswell 2014). The themes were described to draw on their interrelatedness and finally interpreted relative to the context of the study (Adu, 2019). In phase four, we combined themes that seemed to portray similar explanations and deleted themes that seemed not to have valuable information regarding the research question (Nowell et al., 2017:4). The initial ten themes were thus reduced to three themes: (i) Satisfaction with job culture; (ii) Structures for professional development; and (iii) Satisfaction work with recognition and promotion systems.

In phase five we determined what aspect of the data each theme captured and identified what was of interest about them and why (Braun and Clarke, 2006). For example, we looked at the theme, 'satisfaction with job culture' and went through the data to identify which of its aspects related to this theme. We continually reflected on how each theme fitted into the overall story about the entire data set in relation to the research question posed (Nowell et al., 2017:5). Finally, in phase six, we reviewed the themes, and concluded that the three identified themes would enable us to produce our report (Braun and Clarke, 2006). This logical procedure guaranteed a grasp of the presentation and the findings by the researchers.

\subsection{Data Credibility}

Despite the degree of partiality, the researchers ensured trustworthiness, credibility, applicability and consistency of their study (Nieuwenhuis, 2009). To ensure trustworthiness, we made sure that the report contained a rigorous procedural description, which delineated the study purpose, how we conducted it, the processes that led to the various decisions and details of how we generated and managed data were explicit and transparent (Kitto, Chesters, and Grbich, 2008). To ensure credibility, we made sure that the study results offered adequate imageries of the context and that these imageries were familiar to study participants who shared their experiences. We also reflected on the possibility of our influence on the research. Besides, we provided an account of the interpretation process 
by using exact extracts from the data, which the informants supplied, to explain and sustain our interpretations of their meanings (Sandelowski, 1986). To ensure applicability or transferability of the findings, we made sure that our findings could be applied to similar contexts outside the case study situation. To ensure consistency or dependability, we made sure that given the same data, other researchers would have obtained comparable patterns of meanings (Hislop, 2003).

\section{Results}

This section reports the findings of our study based on the qualitative case study design. Interviews were conducted with 6 males and 10 female participants. The themes were identified as '

'Satisfaction with job culture', 'Structures for professional development' and 'Satisfaction work with recognition and promotion systems'.

6.1 Satisfaction with job culture

This theme encapsulates the of feelings about the culture of their institution, the data revealed a general satisfaction with the workplace. Most of the participants indicated they were satisfied with the feelings at their workplace.

7A seemed to be satisfied with the job culture:

I must say that I feel ok with the job I do now. Looking at the logistics needed to perform my duties, everything is intact and anytime you need something too it doesn't take long time for you to get it. So, these are the things that help me and facilitate my work here. So, I feel okay here.

For 7A, being satisfied with the job culture made him feel good:

Despite the challenges I face here, I am happy and proud to be working as administrator.

In contrast, 3B seemed insecure and dissatisfied about the job culture:

Sometimes my work schedules make too much demand on my job and this makes me feel the working climate is not the best. These days, we hear of many death cases: people get worn out due to stress and they die suddenly. This is not good enough.

For instance, $1 \mathrm{~B}$ explained that she had feelings of satisfaction in her current job and she found it to be better than her previous job experience.

I see it relatively good as compared to when I was at the hospital. If anyone came around, you couldn't differentiate between the boss and the workers. We call everyone by their first name. It is a very warm environment.

On the other hand, 4A expressed dissatisfaction with her supervisor. The feelings of not being given the opportunity to make suggestions about her work are expressed in the following excerpt:

My boss uses autocratic style, he hardly listens; ... my boss is autocratic oo; hmm... ...... We don't have much freedom to operate; we are monitored closely unless in very rare times. There is mistrust for one another in the system; I feel our bosses think we have ulterior motives.

5A has the perception that his manager does not care about work performance:

I deal with a laissez-faire superior, which is not good at all. She does not care about the work ... ... I don't think the culture is the best at all. We are not given any feedback on performance and many times, you may have to follow up on issues in order to obtain feedback; it's a pity.

$8 \mathrm{~B}$ seemed to be satisfied with the job culture and to be accommodative:

... I think we get fair support from our superiors and colleagues; there is no big deal about that. I think for the work environment, I think it's normal. It's normal because it's not (always) everything that you will need to work with that you'll get. At times you'll get them at times too you don't. So that I why am saying it's normal.

1A expressed feelings of dissatisfaction with how senior managers treat subordinates:

There is a lot of backbiting for personal favours. This sad because a lot of the time, your superior doesn't even call you to find out the truth. Also, there are a lot of relations in the university. Subordinate does wrong, you give him/her the deserved punishment and the next moment, a superior has a beef with you because he/she relates with that subordinate.

3A expresses her dissatisfaction with the physical resources provided for him. The following excerpt captures his feelings:

The working environment presently [...], I will say that it's not the best. Where we work now, we are quite isolated from the main university. Access to my office is not in the best of (shapes). Currently as we are having this 
interview, outside this very block, the lightening systems are not very good.

6B explains that the job culture is different in the various university departments:

Even though it is the same university, it depends on where you work and the head of department that you work with. I have worked at four places. First at the Dean's Office at Biological Sciences. I was there as a Senior Administrative Assistant, but I was virtually doing the work of a Faculty Officer and I worked there for six months before I was transferred to Entomology and wildlife to be responsible for three departments.

2B seems to have that the job culture at her institution will change for the better:

Satisfaction might be different from you. The world is not perfect, so I can't say everything is perfect. But we are striving that things get well. I believe that things will get better but as it is now, I can't say am fully satisfied.

6.2 Theme 2: Structures for professional development

This theme capture participants' intense feelings about opportunities provided for professional development. Although most of the participants in the two universities did not have dissenting views, one of them seemed to express discriminatory practices regarding opportunities for professional development of administrators. There is a combination of appreciation and despondency.

2A is satisfied about professional development provided in the university. For example, 2A states:

I think the University has a policy on career development but normally depending on what you do, you cannot go out like that. Yes, the university has a policy in place which allow staffs whom have worked for some number of years to be on study leave with pay for their personal career development. The university sometimes fully finances some of these staffs' personal academic development career.

4B also affirms that the university's model for career development issues is satisfactory.

Well, I will say yes since there is a structure there that gives scholarships for staff to pursue based on you meeting the required minimum of service. So, I think the university is on track. I will say yes. In the sense that there are opportunities. Career opportunities for staff. I think this September I enquired and [...] if you want to further your education, they've made forms available to go and declare your [.....]. I think these are some of the avenues.

3A expresses positive feelings about professional development within the university:

When it comes to training in the university, training and development is doing very well. In every year, they write letters to every section in the university requesting the Heads to make available the training needs of their staff and when they are brought to training and development, they prepare their training calendar for the year for all categories of staff and look at the training needs and train them accordingly. They also provide opportunity for newly appointed staff to give them some orientation of their work. It gives them the opportunity to know what they are going to do so that they can do it well, but they [are] also given opportunity to people to apply for study leave, sponsorship. Every year, Training and Development gives an opportunity for people to study both within and outside.

7B expresses a contrary view:

No. I will say no because if you are administrator, you are just there on your own. How you will develop is nobody's business. Professional development, when it comes to administrators for example, even if you take the initiative to develop yourself professionally, even there are other costs that you have to bear yourself. The university doesn't bear any cost when it comes to professional development.

5A has a different view from that expressed by 7B:

The Training and Development of the Human Resource division is not doing much in professional career development for administrators. They could organise intensive professional career development programmes (workshops and seminars) for administrators twice and thrice in a year. So, I wish more opportunities will be provided for me and Administrators in general to develop ourselves. Currently I will say I am satisfied but the other things, as human beings, you always look for more. For instance, as an administrator I need to get certain things that will help my personal development and the development of my work as well.

1A explains that the financial constraints the university faces restrict professional development for all employees within the institution:

I would say but with some reservation and it all depends on the funding issue. I have worked at Training and Development section, so I know the challenges that the University goes through. A lot of staff of all categories would want to develop themselves. The University is willing to do so that is why it has established Training and 
Development Section to train and develop each staff, but the problem is funding.

4A expresses a positive feeling about professional development opportunities provided by the university. Her experience gives her a positive view of professional development support when she mentions:

If for instance I benefited from a scholarship, it is the university that provided the scholarship for me to do the master's programme. They paid everything. It was fully sponsored because I had my salary intact, I was given book allowance, fees were paid throughout the period and (another person receiving a call at the background) I believe if the funding were to be enough, any staff who applies for such a package should be given the opportunity.

6.3 Theme 3: Satisfaction work with recognition and promotion systems

This theme encapsulates each of the participants' experiences about recognition for the work they do and how promotion systems are implemented within their universities. There is a general dissatisfaction expressed among the participants with respect to the way university management via human resource policies handles administrative staff members regarding recognition and promotion systems. They also expressed the view that there was a tendency of unfair rewards and promotion systems and that average support from superiors and colleagues existed.

For example, $8 \mathrm{~A}$ comments:

hmmm, no recognition oo; I have been doing this job for over 8 years and yet the only thing I get is my pay. It demotivates.

6A expresses how she feels promotions are implemented at her university:

promotion is not done fairly in this university; ... some people's promotions are cooked for them.

5B brings attention to discriminatory leadership dimension that inhibits recognition and promotion within her university:

The autocratic leadership style makes one feel worthless so I am not satisfied with my job in this area... having no discretionary powers is not satisfying at all; it does not make me happy with the work I am doing; you express your opinion freely about issues and the next minute, somebody reports you to a superior. Then, this is used against you to deny you of what you genuinely deserve.

8B commented on reward systems as follows:

For over three years now, my appointment has not been confirmed". It's not a good feeling, having no recognition. It demotivates you.

For 1A unfair labour practice inhibits recognition and promotion:

I'm always careful that I don't get conflict because it is dangerous; I'm not too happy with that. Your boss is not treating you fairly, you report to HR and nothing is done about it. The next moment, you are transferred to another unit because your boss says he can't work with you. The system operates as if the superior is always right and the subordinate does not matter.

4B: because of rewards and promotions, I feel like leaving the job; you put in your promotion and it takes like forever before it is processed. And also, before it even comes, you are simply helpless

On reward and promotion structures, many of the interviewees were dissatisfied. An extract by 4B:

Because of rewards and promotions, I feel like leaving the job; you put in your promotion and it takes like forever before it is processed.

3B supports the view by $4 \mathrm{~B}$ on promotion:

When work does not go with timely promotions, worker disaffection arises.

6A states:

No freedom to operate does not augur well for employee creativity and innovativeness. If you're not recognised, you are not motivated to go the extra mile.

These responses represent distressed individuals who are unhappy they are not given due recognition and unhappy about failure of the university system to help them get rewards and promotions. This sentiment is also expressed by 4B:

When work does not go with timely promotions, worker disaffection arises. 


\section{Discussion}

The research question posed for this study is: How do administrators in the two Ghanaian universities perceive organisational climate and job satisfaction? Based on the results of our study the question has been answered through in-depth, individual interviews that were carried out. From the interview data three themes emerged: 'satisfaction with job culture', 'structures for professional development' and 'satisfaction work with recognition and promotion systems'. The three themes summarise the findings of this study.

\subsection{Satisfaction with job culture}

The results indicate that there is a close relationship between organisational climate and employee job performance (Ghanbari and Eskandari, 2014; Tsai, 2014; Adeniji, 2011). This finding is corroborated in several studies by (Goi, 2014; Dimitrios and Koustelios, 2014; Jyoti, 2013) which have identified factors that influence administrators' job satisfaction. The identified factors include interpersonal relationships with colleagues, work conditions, workload, supervision, management, pay, promotion, job security and social status. The finding is further supported by Hunt, and Ivergard (2007), who argue that organisational climate is an idea that pinpoints the organisation's goals and achieves them through amongst others, dedicated and satisfied administrators. Thus, Tsai (2014) posits that the relationship of organisational climate to individual behaviour often emphasises the role of administrators' perceptions on how important their contribution is to the achievement of the overall institutional goals.

Furthermore, Niaz, Minhoon, and Butt (2012) surveyed bank customers and learnt that their perception of the bank's climate was related to a form of bank switching (customer dissatisfaction). Customers who perceived their bank's climate negatively tended to switch banks more frequently than did those who perceived their banks as having an atmosphere centred on client and employee. This finding reinforces that of Muhammad, Rizwan, and Yasin (2012) whose work suggested that salaries not only assist people to attain their basic needs but are also instrumental in satisfying the higher-level needs of people. The results of our study show that most of the participants indicated they were satisfied with the work culture at their universities. According to (Kipkebut, 2010:80) satisfied employees tend to be more committed, productive and happy. We believe that focusing solely on improving an organisation's productivity is no longer sufficient as the key to the survival of universities in today's world.

\subsection{Structures for professional development}

The results of our study indicate that although the two universities generally provide opportunities for professional development, it seems that administrators in both universities are not exposed to the necessary training and career development programmes to execute their tasks effectively, thus resulting in dissatisfaction. However, the results also indicate a combination of appreciation and despondency towards opportunities for professional development. Although funding is not included as a theme for this article, the participants indicated that financial constraints was an impediment in professional development provision for administrators. In their responses the participants felt strongly about the need for professional development. This finding builds on evidence of the significance of professional development for administrators. For example, Yazdanifard (2013) purports that universities that invest in effective training and development of administrative staff tend to achieve both short and long term benefits. Afshan, Irum, and Kamran (2012) argue that training and development should be an important and dynamic function that should enable greater stability, flexibility and capacity for growth among administrators because their functions are versatile within the university operations. However, Eyiah-Wilson, Donkoh, and Brown (2013) in their study of professional development amongst administrators, found that several administrators who went on study leave did not return. It is believed that such people sought better opportunities elsewhere due to poor conditions of service with an attendant poor organisational climate.

\subsection{Satisfaction with recognition and promotion systems}

The results of our study agree with previous research with regard to the significance of staff recognition and promotion where necessary. The finding of our study indicates that almost all of the participants are dissatisfied with the university recognition and promotion systems. Dissatisfaction is expressed through these excerpts: 'employee creativity and innovativeness', 'I feel like leaving the job', 'your boss is not treating you fairly', 'for over three years now, my appointment has not been confirmed', 'promotion is not done fairly in this university', ...'some people's promotions are cooked for them'. The accounts by the participants indicate that the two studied universities in Ghana can hardly achieve their goals and objectives without an effective and contented administrative staff. The kind of dissatisfaction about recognition and promotion systems corroborates Owusu's (2018) research which argues that ostensibly, administrators in the Ghananian universities leave their job because of the perceived dissatisfactory conditions with recognition and promotion systems.

The findings of Sajuyigbe et al., (2013:20) agreed with those of other researchers that many people experience satisfaction when they believe that their prospects are good. This may translate into opportunities for advancement and growth in their current workplace or enhance the chance of finding alternative employment. They maintain 
that if people feel they have limited opportunities for career advancement their job satisfaction may decrease. Assari, Desa, and Subramaniam (2019) suggest that recognition and promotion are important because they can be used to direct the staff towards achieving the goals of the university. We believe that administrators' work is a prime pillar in the sector of education delivery at tertiary levels. While government in Ghana carries out expansionary works in public universities to cater for the yet-to-be-admitted free senior high school students, there is even more need for the universities to retain the required numbers of qualified administrative staff to carry out all scheduled academic programmes. However, there has been a continuous high labour turnover of capable and endowed administrative staff in most of the public universities in Ghana (Owusu, 2018).

\section{Implications for practice}

Opportunities, therefore, for training and development must be of paramount importance in decisions regarding administrator career choices. Both extrinsic and intrinsic job facets should be represented as equally as possible, in composite measure of overall job satisfaction. University faculties and administrators are currently facing many challenges in the execution of their administrative job, a situation that adversely affects their levels of job satisfaction (Goi 2014). This raises concern regarding the attitudes of educators and administrators towards their work and their levels of job satisfaction or dissatisfaction. This study contributes in diverse ways, providing a valuable compact of verifiable ideas, evidence and figures usable by administrators and other stakeholders to comprehend the dynamics involved in ensuring job satisfaction.

\section{Limitations of the study}

The limitations of this study are identified so that the findings can be interpreted correctly within the context of the study. The total population for this study from which the sample was drawn included only two public universities in the Central region of Ghana. Because the study sample was limited to one region, so that other private institutions in the region were precluded and therefore inadvertently ignored. This makes generalisability difficult, so it is recommended that future studies are carried out to investigate the same issues in all public universities within the country, now using a sequential mixed methods design. Another limitation of the study is in the area of the population for the study. The study used public universities in the Central region, and this may affect validity and reliability of the results.

\section{Recommendations}

The study recommends that university management in public institutions should endeavour continually to conduct workshops or seminars to update skills of administrators in their various efforts and at different leadership levels to use situational leadership styles, as suggested by current leadership modules. This would ensure that senior staff function harmoniously with their juniors, thus engendering satisfaction. University management teams should also conduct periodic surveys within their universities in order to determine the availability and adequacy of equipment and resources necessary for the execution of responsibilities of administrators. There should be a procedure in place for feedback to be taken from administrators through periodic checks to departments, sections, and directorates, and for negotiating remedial action with the authorities if necessary. To address the negative impression about organisational climate, university management should make sure that all administrators, irrespective of their rank, receive the needed orientation and administrative support once they join the university so that they become familiar with the workings of the university system.

\section{Conclusion}

In this article, we have attempted to provide an account of how administrators from two universities in Ghana perceive the influence of organisational climate on job satisfaction. From the literature review it is stated that organisational climate is the employees' perceptions and attitudes toward their organisation at any given time. Others relate to the provision of benefits, personnel policies, provision of good working conditions, and creation of a suitable career ladder for academic work. Job satisfaction, on the other hand, is a concept of attitude and an internal state of the individual, associated with a personal feeling of achievement, either quantitative or qualitative. We believe that this study, a novelty of its kind in the Ghanaian public university context, creates research opportunities for further researchers in the field to expand the horizon of knowledge on these variables identified as job satisfaction antecedents.

\section{References}

Abdirahan, HIH, Najeemdeen, IS, Abidemi, BT and Ahmad, RB (2018) The relationship between job satisfaction, work-life balance and organizational commitment on employee performance. IOSR Journal of Business and Management (IOSR-JBM), 20 (5),76-81.

Adeniji, AA (2011) Organisational climate and job satisfaction among academic staff in some selected private universities in southwest Nigeria. Unpublished doctoral thesis, Covenant University, Ogun State, Nigeria. 
Adu, P (2019) Introduction to qualitative data analysis. A step-by-step guide to qualitative data coding. [Online] Available: https://www.drphilipadu.com/(May 8, 2020)

Afshan, S, Irum, S and Kamran ANM (2012) Impact of training on employee performance: A study of telecommunication sector in Pakistan. Interdisciplinary Journal of Contemporary Research in Business, 4(6), 646-652.

Ahmed, AF, Molla, ME and Abed, F (2014) Effect of organizational climate on job satisfaction of clinical instructors at the faculty of nursing, Cairo University. Medical Journal of Cairo University, 82 (2), 17-21.

Assari, MHAH, Desa, NM and Subramaniam, L (2019) Influence of Salary, Promotion, and Recognition toward Work Motivation among Government Trade Agency Employees. International Journal of Business and Management, 14 (4), 48.

Aziri, B (2011) Job satisfaction: a literature review. Management Research and Practice, 3(4), 77-8.

Berberoglu, A (2018) Impact of organizational climate on organizational commitment and perceived organizational performance: Empirical evidence from public hospitals. [Online] Available: https://www.researchgate.net/publication/325523449_Impact_of_organizational_climate_on_organizational commitment_and_perceived_organizational_performance_Empirical_evidence_from_public_hospitals (May 27, 2020)

Bin Shmailan, AS (2016) The relationship between job satisfaction, job performance and employee engagement: An explorative study. Issues in Business Management and Economics, 4 (1), 1-8.

Braun, V and Clarke, V (2006) Using thematic analysis in psychology. Qualitative Research in Psychology, 3(2), $77-101$.

Britten N (1995) Qualitative research: qualitative interviews in medical research. BMJ, 311(6999), 251-253.

Castro, ML and Martins, N (2010) The relationship between organisational climate and employee satisfaction in a South African information and technology organization. South African Journal of Industrial Psychology, 36(1), 1-19.

Creswell, JW (2014) Research design. qualitative, quantitative and mixed methods approaches. 4th ed. Lincoln: Sage Publications.

Das, N (2018) What are the impacts of organisational climate on job satisfaction? [Online] Available: https://www.ilearnlot.com/impact-of-organizational-climate-on-job-satisfaction-dimensions/45436/ (May 7, 2020)

DiCicco-Bloom, B. \& Crabtree, B. F. (2006) The qualitative research interview. Medical Education, 40(4),314-21

Dimitrios, B and Koustelios, A (2014) Organisational culture and job satisfaction: A review. International Review of Management and Marketing, 4(2), 132-149.

Eyiah-Wilson, K., Donkoh, S. A. \& Brown, C. K. (2013). Retention of administrative staff of the Ghana Education Service in the northern region of Ghana. Educational Research, 4(2), 163-173.

Ghanbari, S and Eskandari, A (2014) Transformational leadership, job satisfaction, and organizational innovation. International Journal of Management Perspective, 1(4), 81- 94.

Gaunya, CR (2016) Organizational climate as a determinant of job satisfaction among public sector employees in Kisii county, Kenya. [Online] Available: https://www.semanticscholar.org/paper/Organizational-Climate-asa-Determinant-of-Job-in-Gaunya/4eac6f2326d4d7001cb50f3999e433001b53252d\#paper-(May 27, 2020).

Gaviria-Rivera, JI and Lopez-Zapata, E (2019) Transformational Leadership, Organizational Climate and Job Satisfaction in Work Teams. European Research Studies Journal, 22(3),68-82.

Goetz, K, Campbell, SM, Broge, B and Dörfer, CE (2012) The impact of intrinsic and extrinsic factors on the job satisfaction of dentists. Community Dentistry and Oral Epidemiology, 40(5),474-80.

Goi, MT (2013) Impact of organisational climate on intentions to leave and Job satisfaction. proceedings of Global Business and Finance Research Conference 28- 29 October 2013. Howard Civil Service International House, Taipei, Taiwan.

Hislop, E (2003) Read Me First for a User's Guide to Qualitative Research Janice M Morse Read Me First for a User's Guide to Qualitative Research and Lyn Richards. Nurse Researcher, 10(2), 85-86.

Holloway, J. B. 2012. Leadership Behavior and Organizational Climate: An Empirical Study in a Non-profit Organization. [Online] Available: https://www.regent.edu/acad/global/publications/elj/vol5iss1/ ELJ_Vol5No1_Holloway_pp9-35.pdf(May 7, 2020).

Homans, GC (1958) Social Behaviour as Exchange. American Journal of Sociology, 63(6), 597-606.

Homans, GC (1961) Social Behaviour: Its Elementary Forms. New York: Harcourt, Brace \& World.

Hunt, B and Ivergard, T (2007) Organisational climate and workplace efficacy: Learning from performance measurement in a public-sector cadre organisation. Public Management Review, 9(1), 27-47.

Jameel, B, Shaheen, S, and Majid, M. (2018) Introduction to qualitative research for novice investigators. Undergraduate Research in Natural and Clinical Science and Technology (URNCST) Journal, 2(6), 1-6.

Jyoti, J (2013) Impact of Organizational Climate on Job Satisfaction, Job Commitment and Intention to Leave: An Empirical Model. Journal of Business Theory and Practice, 1 (1), 66-82. 
Kieserling, A (2018) Exchange and power in social life. Netzwerkforschung, 51-54.

Kipkebut, DJ (2010) Organisational commitment and job satisfaction in higher educational institutions: the Kenyan case. $\mathrm{PhD}$ thesis. Middlesex University.

Kitto, SC, \& Chesters, J and Grbich, C (2008) Quality in qualitative research. The Medical Journal of Australia, $188(4), 243-246$.

Lincoln, Y and Guba, EG (1985) Naturalistic inquiry. Newbury Park, CA: Sage.

Muhammad, E M, Rizwan, QD and Yasin, M (2012) The impact of pay and promotion on job satisfaction: evidence from higher education institutes of Pakistan. American Journal of Economics, Special Issue: 6(9), 279-298.

Newby, P (2010) Research methods for education. London: Pearson.

Niaz, AB, Minhoon KL and Butt, FD (2012) A comparative study of organisational climate and job satisfaction in public, private and foreign banks. Asian Social Science, 8(4), $259-267$.

Nieuwenhuis, J (2009) Analysing qualitative data. Pretoria: Van Schaik, (Chapter 6).

Nowell, LS, Norris, JM, Whitel, DE and Moules, NJ (2017) Thematic Analysis: Striving to Meet the Trustworthiness Criteria. International Journal of Qualitative Methods, 16, 1-13.

Okoli, IE (2018) Organisational climate and job satisfaction among academic staff: Experience from selected private universities in southeast Nigeria. International Journal of Research in Business Studies and Management, 5(12), 36-48.

Okoli, IE \& Monanu, OG (2016) An exploratory study of job insecurity as a correlate of employees' affective commitment. International Journal of Research in IT, Management and Engineering, 6(10), 1-6

Owusu, GA (2018). Influence of organisational climate on job satisfaction among administrative staff of two public universities in Central Region of Ghana. [Unpublished Doctor of Education degree]. Pretoria: University of South Africa.

Owusu, AG and Owusu, AA (2014) Impact of administrators' work and the physical plant on learning: Perspectives of lecturers and students in the university of Cape Coast. Journal of Emerging Trends in Educational Research and Policy Studies (JETERAPS), 5(2), 215-222.

Pangil, F, Yahya, KK., Johari, J, Md Isa, MF and Daud, Z (2011) The relationship between organisational climate and job satisfaction: The case of a government agency in Malaysia. International Journal of Humanities and Social Science, 1(12),152-160.

Sajuyigbe, AS, Olaoye BO and Adeyemi MA (2013) Impact of reward on employees' performance in a selected manufacturing companies in Ibadan. International Journal of Arts and Commerce, 2(2), 12 - 32.

Sandelowski, M (1986) The problem of rigor in qualitative research. Adv Nurs Sci, 8, 27-37.

Telman, N and Unsal, P (2004) Calisan Memnuniyeti. Istanbul: Epsilon Publishing.

Tiwari, G (2017) What is Social Exchange Theory and Explanation. [Online] Available: https://www.sociologygroup.com/social-exchange-theory/(May 7, 2020).

Tsai, C (2014) The organisational climate and employees' job satisfaction in the terminal operation context of Kaohsiung port. The Asian Journal of Shipping and Logistics, 30(3), 373 - 392.

Turner, DW (2010) Qualitative interview design: A practical guide for novice investigators. The Qualitative Report, 15(3), 754.

Wong, LP (2008) Data Analysis in Qualitative Research: A Brief Guide to Using Nvivo. Malays Fam Physician, 3(1),14-20 Yazdanifard, M. (2013). The impact of employee training and development on employee productivity. [Online] Available: https://www.researchgate.net/publication/260219097_THE_IMPACT_OF_EMPLOYEE_TRAINING_AN D_DEVELOPMENT_ON_EMPLOYEE_PRODUCTIVITY (June 11, 2020)

Yin, $\mathrm{R} \overline{\mathrm{K}}$ (2017) Case study research and applications: Design and methods. London: Sage Publications. 